\title{
Simón Bolívar y las cantáridas
}

\author{
Walter Ledermann D.
}

\section{Simon Bolivar and the cantharides}

Simon Bolivar, The Liberator, did not trust medical care and if he ever requested a doctor, it seems to have been mainly politically motivated. Unfortunately his fears seem to have been correct as his death was accelerated by Dr. Revenand, a man whose medical title is yet under discussion, who applied an extract of cantharides, a beetle known as "the Spanish fly", employed generally as an aphrodisiac, over Bolivar's neck region. According to popular belief of the time, cantharidin, the insect's active principle, reduced "the excess of humours", such as cerebrospinal fluid, plasma, "pituita" and others. Cantharidin has severe adverse effects and was for sure the origin of great suffering for many unfortunate patients in the past.

Key words: Bolivar, Tuberculosis, Révèrend, Cantharide.

Palabras claves: Bolívar, Tuberculosis, Révèrend, Cantárida.

La muerte de grandes guerreros ocurrida en el lecho y no en el campo de batalla ha sido siempre un atractivo $\mathrm{y}$, por desgracia, insoluble desafío para los historiadores de la medicina. Así, los análisis y discusiones de las posibles causas de muerte de Alejandro, de Atila y de Napoleón, podrían ocupar volúmenes y continuarían sin resolverse, pues faltan los indispensables estudios de laboratorio, inexistentes en aquellas épocas, siendo preciso fiar de aproximaciones y descripciones clínicas puramente subjetivas, parciales e imposibles de verificar.

En América latina el mejor ejemplo lo constituye el enigma del fallecimiento de Simón Bolívar, aun existiendo en este caso una autopsia, pero ella es imperfecta, incompleta y sólo macroscópica, perpetrada por un médico de cuyo título y capacidades se duda hasta hoy día, lo cual la inhabilita para establecer cualquier conclusión valedera.

La aproximación más definida y aceptada es que el Libertador murió de tuberculosis. Sorprende que todavía, en el siglo XXI, se siga dando valor al antecedente de haber fallecido su padre de esta enfermedad, como

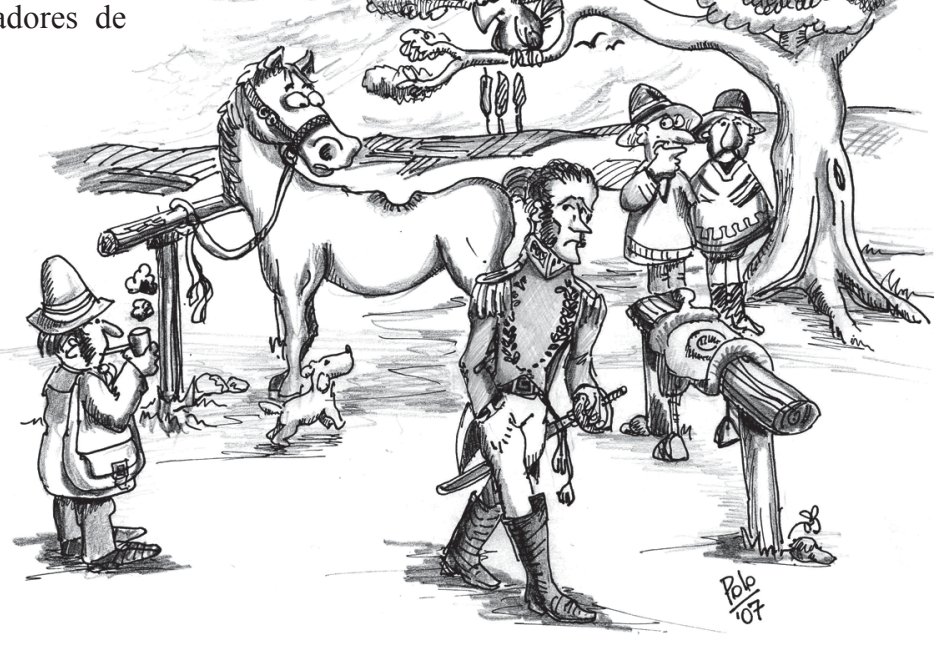

si el bacilo de Koch fuese hereditario. Que sus progenitores hayan sufrido este mal y que él mismo desarrollara un complejo primario en su infancia, nada tienen de extraordinario, debiendo haber sido ésta una situación más que frecuente en la Venezuela de entonces: muchos enfermaban y otros tantos, más afortunados, escapaban, como sus hermanos y la mayoría de sus compañeros de armas.
De la madre se dice que "era débil de pulmones", por lo cual ni pudo amamantarlo ni ocuparse de su crianza, mientras de su padre se describe un "hábito tísico", que también ha querido asignarse al héroe. De éste tenemos descripciones escuetas, que lo retratan, cuando estaba sano, como un hombre pequeño, de sólo 1,62 metros de altura; otros biógrafos, más generosos, lo describen de talla mediana o algo por debajo la mediana. Mencionan que tenía el tórax estrecho, brazos largos y piernas delgadas y que su peso no superaba los 45 kilos, estructura menguada que no se compadece con los relatos de sus proezas físicas, pues vencía a correr y a nadar a los hombres más rudos del llano venezolano, siendo increíble su resistencia para las infinitas marchas a caballo. Al respecto, se calcula que recorrió más de 5.000 millas en sus campañas y se relata que alrededor del ciezo, nombre castizo con que entonces se designaba al ano, de tanto montar había desarrollado una callosidad circular, por la cual ganó el cariñoso apodo de "culo de hierro"" 
Karl Marx, en un curioso artículo de 1858, cita una descripción de Ducoudray- Holstein: "Mide cinco pies y cuatro pulgadas, su rostro es enjuto, de mejillas hundidas y de tez pardusca y lívida; los ojos, ni grandes ni pequeños, se hunden profundamente en las órbitas, su cabello es ralo... Todo su cuerpo es flaco y descarnado..."2.

Simón Bolívar descreía de los médicos y de sus medicinas, y aunque fueron varios quienes lo trataron, sólo mostró cierto apego por aquél que no era inclinado a extender recetas. Sabia visión del Libertador, cuya aguda inteligencia le permitía percatarse de la irracionalidad e inutilidad de los procedimientos y medicamentos empleados en el siglo XIX, calificativos que, sin duda, en cincuenta años más se darán a los que usamos actualmente.

En la historia médica de Simón Bolívar hay tres puntos en que se detienen todos los investigadores. El primero es el episodio de Pativilca, lugar geográfico a "tres jornadas" de Lima, donde a principios de 1824, a la edad de 40 años, sufrió una enfermedad de orden entérico o puramente febril. Según su biógrafo Joaquín Mosquera, Bolívar habría sido afectado por el tabardillo, voz con que se describía por entonces el tifus exantemático, que parece haber sido endémico en la región, aunque también los soldados llamaban así a la insolación. El médico Florence O’Leary, oficial de la legión Británica, sostenía el vago diagnóstico de "fiebre cerebral", tan caro a los escritores europeos de la época, principalmente a los rusos, como Chéjov, quien, aun siendo médico, no trepidaba en sumir a sus heroínas en este misterioso mal tan pronto sufrían una contrariedad sentimental. También se ha planteado con posterioridad que pudiera haber sido una disentería amebiana, pues hay antecedentes de posibles brotes de esta parasitosis en 1824 y $1829^{3}$.

El caso es que este tabardillo, fiebre cerebral, o lo que fuera, dejó al Libertador en los huesos, pues estuvo ocho días con fiebre violenta, delirando y tosiendo, presa de vómitos y cólicos angustiosos, sudando frío, para terminar con "las piernas descarnadas, la voz hueca y débil y el semblante cadavérico". Ahí fue cuando, interrogado por Mosquera sobre qué pensaba hacer, acosado como estaba por la enfermedad y por sus enemigos políticos, soltó la brevísima frase para el bronce:

- Triunfar 4 .
El segundo hito es la famosa noche limeña del atentado contra su vida, en septiembre de 1828, del cual lo salvara la decisión y el coraje de su amante Manuelita Saénz, quien lo sacó por la ventana y lo escondió bajo el puente del Carmen, en el río San Agustín. Allí, en esa noche terrible, tiritando a orilla de las aguas, parece que adquirió una neumonía o se agravó su tisis. Nuevamente aparece don Joaquín Mosquera, quien lo obliga a guardar cama, pues estaba "con semblante pálido y melancólico, afectado de una tos seca pulmonar". Pero, más que la noche fría, lo afectó anímicamente que fueran capaces sus adversarios de llevar su odio al punto de atentar contra su vida: si aceptamos la decisiva influencia de la mente sobre los males orgánicos, podría decirse que en ese instante comenzó el fin del gran héroe ${ }^{1}$.

Y llegamos al tercer punto, en el año de su muerte, acaecida el 17 de diciembre de 1830 en la quinta de San Pedro Alejandrino, cerca de la ciudad de Santa Marta. Desde hacía un año su salud venía deteriorándose a pasos agigantados, tanto que "ya no podía andar a caballo dos horas continuas sin fatigarse", lo que es mucho decir para un jinete como "culo de hierro". De esa época, durante su estancia en Bucaramanga, es su famosa frase sobre los médicos. El doctor Moore le habría recetado un vomitivo, brutalidad médica común por entonces, y el Libertador, con su característica sagacidad, dijo que no lo tomaría, estableciendo de paso la célebre comparación entre los galenos y los obispos -"aquéllos dan recetas y éstos bendiciones"- agregando, a manera de explicación, que "mi médico es para mí un mueble de lujo y aparato, no de necesidad; lo mismo me pasa con mi capellán, a quien he despachado".

Bolívar fue atendido en su vida por muchos médicos. Siendo escasos los nativos, casi todos fueron ingleses, como el mencionado Moore, O’Leary, Murphy, Burton, Cheyne Night y Foley. No creyó en ninguno, pero cuando se vio muy enfermo, al final de su carrera, pidió "con mucha urgencia un médico", diciendo luego, como niño porfiado que no quiere remedios, "prefiero la muerte a las medicinas: les tengo una repugnancia que no puedo vencer"s.

Volviendo al tercer hito médico, que se inicia el 8 de mayo de 1830, cuando salió de Bogotá hacia Cartagena a las seis de una mañana "lluviosa y triste", sin tener muy claro del todo su itinerario, que abarcaría un largo viaje por tierra y luego por agua, navegando el Magdalena. De Cartagena pensaba ir a Inglaterra, pero ahí lo pilló la noticia del asesinato de su gran amigo Sucre, que lo desmoronó anímicamente. Vacilante, eligió el camino a Santa Marta, pero la lluvia, los dolores, la fiebre intermitente, lo hicieron recalar a la fuerza en la Villa de la Soledad, profético nombre, donde lo visita un médico que se gana su simpatía, pues era también enemigo de los medicamentos: el doctor Hércules Gastelbondo. Don Hércules fue sólo de visita social, pero encantó a Bolívar por emplear lo que hoy llamaríamos, bondadosamente, medicina de alternativa, y tanto lo encantó que siguieron viaje juntos, para embarcarse luego el Libertador en el buquecillo "Manuel", siempre con destino hacia Santa Marta, aunque Gastelbondo vaticinara que no soportaría el viaje, tan mala estaba su salud. En Santa Marta lo desembarcaron en andas, "apenas con un soplo de vida": ahí encontró al doctor Révérend y, con él, la muerte.

Hasta hoy día se discute si este francés era o no médico, con pruebas y contrapruebas en uno u otro sentido. El punto es irrelevante, pues el conocimiento médico en los primeros treinta años del siglo XIX no era más "científico" que el del vulgo. Si bien los cirujanos eran hábiles y efectivos, aun cuando mutilantes, los internistas aportaban a la salud poco más que los charlatanes: sólo en los últimos treinta años de dicha centuria, con el advenimiento de la microbiología comenzó a encenderse la luz de la ciencia, pues bien sabemos los infectólogos que todas las enfermedades y traumas son de origen microbiano, y si se clasifican las patologías en endocrinas, metabólicas, etc, es sólo como un ordenamiento, con fines puramente didácticos.

El doctor Révérend acertó al postular que Bolívar sufría de una lesión pulmonar, cosa que era evidente con sólo oírlo toser, en tanto que el doctor Night (o McKnight) -jotro inglés!- se inclinaba por el paludismo, cosa que, probablemente, también sufría. En todo caso, estuvieron de acuerdo en llevarlo al campo, a la quinta de San Pedro Alejandrino, donde hizo testamento y recibió la visita del obispo Estévez, con quien se encerró durante un cuarto de hora, al cabo del cual salió el religioso "demudado", no se sabe si por alguna herejía del enfermo o por encontrarlo agónico, en tanto que Bolívar le 
soltaba a su servidor José Palacios la frase que motivara el libro de García Márquez "El general en su laberinto":

- ¡Carajo! ¿Cómo voy a salir de este laberinto? ${ }^{6}$.

Quienes quedaron metidos en un laberinto, sin salida hasta ahora, fueron los médicos, tanto los tratantes de entonces como los historiadores de hoy. Borges, que era aficionado a los laberintos y tiene más de un relato sobre ellos, pudiera haber escrito un texto superior al del autor colombiano. Recordemos tan sólo la historia de aquel rey árabe que, de visita al monarca de Babilonia, es vejado por éste, al ser introducido en un laberinto del que sale únicamente por la gracia de Dios, para regresar más tarde con un ejército, asolar el país y capturar a su ofensor, al cual lleva al medio del desierto, donde lo abandona para que muera de hambre y de sed, diciéndole:

- En Babilonia me quisiste perder en un laberinto de bronce con muchas escaleras, puertas y muros; ahora el Poderoso ha tenido a bien que te muestre el mío, donde no hay escaleras que subir, ni puertas que forzar, ni fatigosas galerías que recorrer, ni muros que te veden el paso ${ }^{7}$.

Para Simón Bolívar la salida fue fácil, pues tuvo la ayuda de Révérend, quien le recetó unos vesicatorios o vejigatorios, que aceleraron su fin. Éstos constituían un remedio muy popular para "sacar los humores", consistiendo en emplastos o parches con sustancias irritantes para la piel, provocando enrojecimiento y luego vesículas (de ahí su nombre) y hasta ampollas, según la dosis. Entre las porquerías empleadas, la preferida era el extracto de cantáridas

A estos insectos, del cual el más conocido es la especie Lytta vesicatoria, ya descritos y empleados por Hipócrates en la antigüedad, se les han atribuido virtudes afrodisíacas, ya sea aplicados en forma tópica desecada y convertidos en polvo, o macerados y diluidos como elixir de amor : se dice que en esta forma la administraba el célebre Casanova a sus amadas ${ }^{8}$.

Las cantáridas son el origen de una maliciosa y equívoca expresión popular para aludir al coito: echar un polvo. Curiosamente, en su inicio describía una intención; en la actualidad, la consumación. Era sabido que las mujeres de los caciques araucanos, cuando éstos envejecían y perdían vigor viril, les administraban subrepticiamente un macera- do de cantáridas en su dieta. Los conquistadores, que conocían a la Lytta bajo el nombre de "mosca de España", prohijaron la idea, de manera que su uso se popularizó en los campos, como un antecesor del viagra y como afrodisíaco, para persuadir a las castas doncellas a dejarse de remilgos.

El insecto, una vez muerto, se dejaba secar por completo y luego se molía: una celestina cercana a la joven víctima debía echar el polvo en sus medias para que, por contigüidad, excitara sus zonas pudendas. De allí nació la expresión "echarle un polvo", que describía la artera asechanza, más no la consumación, que nunca llegaba, pues todos estos remedios mágicos, "de la naturaleza", siempre "le han resultado" a un amigo de un conocido de una tía, pero nunca al cándido de turno que los emplea, pese a lo cual la fe en el sucio milagro nunca decae; y si algún efecto tiene, debe ser sólo un desagradable prurito.

La Lytta vesicatoria, un coleóptero verdoso de unos $2 \mathrm{~cm}$, fue descrito y clasificado por Linneo en 1758. Su principio activo, la cantaridina (C $10 \mathrm{H} 12 \mathrm{O} 4$ ), produce rubefacción de la piel, pudiendo llegar a formar vesículas, y por ello se usaba en medicina antigua como vesicante en el tratamiento de úlceras, o "para eliminar humores", finalidad ésta con que se le habría aplicado como ungüento en la nuca a Simón Bolívar. Es curiosa la similitud de su empleo con el viagra, pues la cantárida se empleaba para tratar la alopecia, descubriéndose luego que, como efecto secundario, en algunos varones causaba priapismo9. Por misteriosos caminos, la historia siempre se repite.

De un antiguo diccionario médico hemos extraído una extensa información sobre el uso de las cantáridas, que pasamos a resumir.

La cantárida, dice el desconocido autor, es un coleóptero oriundo de España (mosca española), que mora en las plantas oleáceas y lonicéridas Catarsis vesicatoria y Maloe vesicatorius. Contiene como principio activo la cantaridina, descubierta por Robiquet en 1812, que cristaliza en tablas o prismas incoloros (C $5 \mathrm{H} 6 \mathrm{O}$ 2). Es poco soluble en agua y en alcohol, pero sí en lejía de potasa, aceites y grasas. Se encuentra en todo el cuerpo del insecto, pero especialmente en el abdomen y no se forma por completo hasta que el coleóptero madura, confiriéndole un olor "sumamente fuerte y desagradable".
La cantaridina obra en forma tópica, produciendo una inflamación local, pero como se absorbe puede provocar efectos sistémicos, siendo los más constantes los que afectan al sistema génito-urinario. Aplicado sobre la piel como un emplasto, a las tres horas produce rubor y, en el curso de 8 a 12 horas, vesículas con un líquido claro y amarillento, que confluyen hasta formar bulas. Especialmente en los niños pueden producirse en forma paralela, al absorberse, disuria y albuminuria.

Precisa el autor que mayores son las posibilidades de intoxicarse si se da a beber, generando tenesmo vesical, prurito y ardor uretrales y, a veces, excitación genésica, con erecciones y, rara vez, ninfomanía.

La intoxicación se produce con dosis altas, cuando es usada con fines afrodisíacos o abortivos. También ocurre, agrega el experto del siglo XIX, al equivocar su polvo con la pimienta o su tintura como aguardiente. Se llega a la retención de orina, erecciones dolorosas en el hombre y metrorragias en la mujer, diarrea mucosa y sanguinolenta, bradicardia, lipotimia, delirio, coma y muerte, que se alcanza con 1,5 a 3 gramos de polvo o 35 gramos de tintura: Heinrich relata un suicidio con 0,01 gramo de cantaridina ingerida.

Por estos accedentes, ya en época de Bolívar su empleo se había reducido al uso tópico exclusivamente, en dosis de 0,01 a 0,05 gramos mezclados con opio o alcanfor, como emulsión o desecada para reducir a polvo. En forma artesanal, se puede obtener el polvo (pulvis cantharidium) secando el insecto al sol o en estufa, pulverizándolo luego en un mortero y tamizándolo. Para obtener un buen emplasto o vejigatorio (emplastum cantharidium) se necesitan tres partes de polvo, una de aceite de oliva y dos de cera amarilla, colofonia y trementina de pino. También, con algunas variantes, pueden fabricarse el papel epipástico (charta epipatica), el unguentum cantharidium y la tinctura alcoholicum cantharidium, preparándose esta última con polvo de cochinilla, alcohol de $80^{\circ}$ y alcohol de canela, con lo cual queda muy útil para fricciones ${ }^{10}$.

El doctor Réverend redactó 33 boletines sobre la salud de su paciente, en el breve tiempo que lo atendió profesionalmente. En los números 11 y 12, emitidos cinco días antes del deceso, consigna la existencia de "síntomas de congestión en el cerebro". Para extraer los humores que provocaban dicha 
plétora, procede a aplicarle vejigatorios, a razón de uno por día. Sorprende que, siglos después de Vesalio, todavía algún médico pudiera creer posible extraer líquido del encéfalo produciendo vesículas en la piel, pero así pensaba Révérend. En los últimos de sus 33 boletines se habla primero de incontinencia urinaria y luego de orina escasa y sanguinolenta, hasta anuria total, añadiendo que las sensaciones estaban entorpecidas, estando el enfermo estuporoso, confuso, balbuceando en su desvarío y delirando de continuo... ¡Toda la sintomatología típica de la intoxicación por cantaridina!

El francés, hombre diligente, practicó la autopsia al héroe, encontrando lesiones pulmonares, que no vaciló en calificar de tuberculosas:

"2.-Pecho. De los lados posterior y superior estaban adheridas las pleuras pulmonares a las pleuras costales por producciones semimembranosas; endurecimiento en los dos tercios superiores de cada pulmón, el derecho, casi desorganizado, presentó un manantial abierto de color de las heces del vino, jaspeado de algunos tubérculos de diferentes tamaños, no muy blandos; el izquierdo, aunque menos desorganizado, ofreció la misma afección tuberculosa, y dividiéndola con el escalpelo se descubrió una concreción calcárea irregularmente angulosa, de tamaño de una pequeña avellana. Abierto el resto de los pulmones con el instrumento, derramó un moco pardusco, que por la presión se hizo espumoso. El corazón no ofreció nada particular, aunque bañado en un líquido ligeramente verdoso, contenido en el pericardio".

La vejiga estaba vacía y pegada al pubis, en tanto que los riñones se describen como normales. La conclusión es un "catarro pulmonar, que habiendo sido descuidado pasó al estado crónico y consecutivamente degeneró en tisis tuberculosa" 11.

Del mal causado por sus vejigatorios no hay conciencia alguna : Révérend, como tanto ignorante, no se cuestionaba. El profesor de Anatomía de la Universidad Central de Venezuela, don José Izquierdo, afirma que el francés no era médico, pues su nombre no figura en el archivo de la Facultad de Medicina de Paris, ni en ningún otro instituto francés que daban enseñanza médica en la segunda y en la tercera década del siglo
XIX, únicas que podrían corresponder a sus estudios médicos. Agrega que, al pedir a los respectivos Congresos de Bogotá y de Caracas el título honorario de Médico Mayor del Ejército, el de Bogotá se negó con cortesía y el de Caracas le contestó que carecía de título universitario ${ }^{12}$.

Por su parte, el doctor Héctor Réverend Pacheco, descendiente directo del médico de Bolívar, lo defiende y relata que poseía el título, pero sin aportar pruebas:

"En febrero de 1796 nació en Falaise, Normandía. Estudió en el Liceo de Caen. En 1814 se alistó como soldado en el cuerpo de caballería de Napoleón y participó en la desgraciada campaña del Loire en 1820. Radicado en París, estudió medicina ( no dice dónde ni precisa fechas). Partidario ardiente de las ideas republicanas y creyéndose inseguro en Francia, se dirigió a Colombia y arribó a Santa Marta en 1824. Allí fue médico del hospital militar, miembro de la Junta de Sanidad y Cirujano Mayor del ejército en 1830"...1.

Corrobora su espíritu republicano y libertario el diálogo que habría sostenido con su ilustre paciente, de acuerdo al texto del historiador chileno Campos Menéndez:

- ¿Por qué vino usted a América?- pregunta el enfermo.

- Para buscar la libertad- le contesta el médico.

- ¿Y la encontró usted?

- ¡Ciertamente, Excelencia!

- ¡Oh! -musita, melancólico, el héroe-: ¡entonces usted ha sido más afortunado que yo! ${ }^{13}$.

Pero analicemos sus probables estudios médicos: si participó en la campaña del Loire en 1820 y después se radicó en París, lo tenemos ya de 24 años iniciando estudios de medicina, pero tan pronto como en 1824 estaba en Colombia, de modo que difícilmente llegó a estudiar cuatro años... Entonces, no estaba titulado y el Congreso de Caracas tenía razón. En su descargo, diremos que no cobró honorarios, expresando: "¿qué más premio que el insigne honor de haber sido su médico?.

En realidad, para prueba de que no era titulado, basta con oír sus razones para aplicar los vejigatorios: "la materia morbífica, por el movimiento metastático del pecho, subía a la cabeza...".

También hay razones para pensar que lo era , como el hecho de haber acompañado al paciente hasta su último minuto, pues bien sabemos que, si el médico a veces no puede curar, siempre debe acompañar y consolar al enfermo. De acuerdo al mencionado Campos Menéndez, “cuando, al mediodía, llega el médico, apenas percibe ya su pulso. En la antecámara, sumida en dramático silencio, montan su última guardia los duros soldados de la independencia. El doctor Révérend abre la puerta:

- Señores -anuncia con voz helada- si queréis presenciar los últimos alientos del Libertador, ya es tiempo".

Cuando ellos entran, la Lytta vesicatoria se retira zumbando por la ventana.

\section{Referencias}

1.- Vergara I, Toro G. El Libertador y su médico el Dr. Révérend. En: Opiniones, debates y controversias. www.revmed.unal.edu.co/ revistafm/v53n2/v53n2A7.htlm

2.- Marx C. Bolívar y Ponte (1858). Archivo Marx/Engels. Edición alemana de MEW, XIV: $217-31$

3.- Torres A M. Simón Bolívar. Su muerte; los médicos. www.simon-bolivar.org

4.- Mijares P A. El Libertador. Monte Avila Editores, Caracas 1998.

5.- Polanco T. Simón Bolívar. Ensayo sobre una interpretación biográfica a través de sus documentos. $4^{\mathrm{a}}$ edición. Editorial EG, Barcelona 1999.

6.- García Márquez G. El general en su laberinto. La Oveja Negra, Bogotá 1989.

7.- Borges JL. El Aleph. Emecé Editores S.A., Buenos Aires 1957; 135-6.

8.- Geisser A. La cantárida. Entre amor y veneno mortal www.caiman.de/spanien/ fliege/fliegees.shtml.

9.- Lytta vesicatoria. wikipedia.org

10.- Eulenburg A. Cantáridas. Diccionario Enciclopédico de Medicina y Cirugía. Traducido directamente y arreglado para uso de médicos españoles por el doctor Isidoro de Miguel y Viguri. Agustín Jubera, editor, Madrid 1886; XI : 282-5.

11.- Serpa Flores F. Muerte de Bolívar. Tribuna Médica 1991; 344-50.

12.- Izquierdo J. ¿Fue médico Révérend? En: Simón Bolívar, reseña histórica. www.simon-bolívar.org/bolivar/reverendmedico.htlm

13.- Campos Menéndez E. Se llamaba Bolívar. Editorial Francisco de Aguirre, S. A., Buenos Aires 1975. 